九州大学学術情報リポジトリ

Kyushu University Institutional Repository

\title{
Effect of Urea Addition on Soda Pulping of Oak Wood
}

Cho, Nam-Seok

Wood and Paper Science, Chungbuk National University

Matsumoto, Yuj i

Graduate School of Agricultural and Life Sciences, University of Tokyo

Cho, Hee-Yeon

Keck School of Medicine, University of Southern California

Shin, Soo-Jeong

Wood and Paper Science, Chungbuk National University

他

https://doi.org/10.5109/10061

出版情報: 九州大学大学院農学研究院紀要. 53 (1)，pp. 1-5，2008-02-28. Faculty of Agriculture， Kyushu University

バージョン :

権利関係 : 


\title{
Effect of Urea Addition on Soda Pulping of Oak Wood
}

\author{
Nam-Seok CHO ${ }^{1}$, Yuji MATSUMOTO ${ }^{2}$, Hee-Yeon $\mathrm{CHO}^{3}$, \\ Soo-Jeong SHIN ${ }^{1}$ and Shoji OHGA*
}

\author{
Laboratory of Forest Resources Management, Division of Forest Ecosphere Management, \\ Department of Forest and Forest Products Sciences, Kyushu University, \\ Sasaguri, Fukuoka 811-2415, Japan \\ (Received November 1, 2007 and accepted November 30, 2007)
}

\begin{abstract}
Many studies have been conducted to find a sulfur-free additive for alkaline pulping liquors that would have an effect similar to that of sulfide in kraft pulping. Some reagents that partially fulfill this role have been found, but they are too expensive to be used in the quantities required to make them effective. As an alternative method to solve air pollution problem and difficulty of pulp bleaching of kraft pulping process, $\mathrm{NaOH}-$ Urea pulping was applied. The properties of $\mathrm{NaOH}-$ Urea pulp were compared to those of $\mathrm{NaOH}$ and kraft pulps. Addition of urea in low alkali charges retarded delignification rate compared to $\mathrm{NaOH}$ pulping. But, in high alkali application, delignification was significantly enhanced not from the addition of urea but from the high alkalinity. It was disclosed that urea did not participate on delignification reaction by the experiment using lignin model compound. Compared to paper strengths at the same level of sheet density, $\mathrm{NaOH}-$ Urea pulp gave as almost same breaking length and tensile index as those of kraft pulp. Especially tensile energy absorption and burst index were higher than those of kraft pulp. It is believed that, during pulping, the formation of cellulose carbamate would play a main role to enchance the paper strength.
\end{abstract}

\section{INTRODUCTION}

The problems arising from the release of sulfur compounds during kraft pulping and recovery have led to the investigation of sulfur-free pulping methods as possible alternatives. Many approaches have been considered, including the alkali process, the application of oxygen to the delignification process (Abrahamson and Samuelson, 1979; Aoyagi et al., 1977; Worster and Pudek, 1974), and the use of organic additives (Abbot and Bolker, 1982; Daima et al., 1978; Nakano et al., 1976; April et al., 1982; Sakakibara, 1983) to perform a role similar to that of sulfide in the kraft process. These additives may be used to allow complete removal of sulfide from the system or to reduce the sulfidity level during digestion to a point where odor from the black liquor system is more readily controlled. Many studies (Kalish, 1967; Huynh et al., 1982; Cho, 1983; Worster and Pudek, 1974a; 1974b) have been conducted to find a sulfur-free additive for alkaline pulping liquors that would have an effect similar to that of sulfide in kraft pulping. Some reagents that partially fulfill this roll have been found, but they are too expensive to be used in the quantities required to make them effective.

One type of reagent, namely anthraquinones and compounds of a related structure (Flemming et al., 1978; Ghosh et al., 1978; Holton and Chapman, 1977;

${ }^{1}$ Wood and Paper Science, Chungbuk National University, Cheongju 361-763, Korea

${ }^{2}$ Graduate School of Agricultural and Life Sciences, University of Tokyo, Tokyo 113-8657, Japan

Molecular Microbiology and Immunology, Keck School of Medicine, University of Southern California, Los Angeles, CA 90089, USA

* Corresponding author (E-mail: ohga@forest.kyushu-u.ac.jp)
Obst, 1979; Yaguchi, 1979), has been found to have a marked effect on kraft and alkali pulping, even in very small quantities. Although some research works on $\mathrm{NaOH}-$ Urea pulping (Tripath and Basu, 1967; Draganova et al., 1971; Lyubavskaya and Voronova, 1977; Popescu and Nita, 1983) have been done, most of them were mainly about the effect of urea additive on delignification, there were few papers on the sheet properties of $\mathrm{NaOH}-\mathrm{Urea}$ pulp. This study was performed to find out the effect of urea addition to $\mathrm{NaOH}$ cooking liquor on the pulping of oak wood and its pulp properties.

\section{EXPERIMENTAL}

\section{Pulp preparation}

Oak wood chips were cooked in a 51 . capacity stainless steel digester, using liquor to wood ratio, 8:1, time to maximum temperature, 90 min., at maximum temperature of $170{ }^{\circ} \mathrm{C}$ for the certain cooking times. Charges of $350 \mathrm{~g}$ (O.D.) chips were used for the $\mathrm{NaOH}$ and $\mathrm{NaOH}-$ Urea cooks, with active alkali of $18 \%$. Charges of urea in alkali cooking media were 4 and 8\% based on wood chip. Kraft pulp was prepared by cooking $350 \mathrm{~g}$ chips using a 18\% active alkali and sulfidity of $25 \%$. Cooked chips were disintegrated, thoroughly washed, dewatered to a moisture content of ca. $90 \%$, crumbed in plastic bags without screening and stored in refriegerator for the next processing. In order to confirm the effect of urea addition during $\mathrm{NaOH}$ cooking on delignification, lignin model compound, guaiacylglycerol- $\beta$-guaiacyl ether (GG ether), was synthesized by Hosoya's method (Hosoya and Nakano, 1980) and subjected to $\mathrm{NaOH}$ and $\mathrm{NaOH}-U$ rea cooks. Degradation product from GG ether was determined by G.L.C. 


\section{Pulp evaluation}

Pulps were beaten in a PFI mill with a $30 \mathrm{~g}$ (O.D.) charge at $10 \%$ stock consistency using a beating load of $3.4 \mathrm{~kg} / \mathrm{cm}$ and a relative speed of $6 \mathrm{~m} / \mathrm{s}$. Handsheets (ca. $60 \mathrm{~g} / \mathrm{m}^{2}$ O.D. Grammage) were prepared from 3 different freeness level pulps according to Korean Standard. Handsheets were tested according to Korean Standard methods after conditioning in an atmosphere of $50 \pm 2 \%$ of relative humidity at $23 \pm 1{ }^{\circ} \mathrm{C}$. Water retention values of pulps also were determined by the procedure using centrifugal forces of $3000 \mathrm{G}$ for $15 \mathrm{~min}$.

\section{RESULTS AND DISCUSSION}

\section{Pulping}

The variation in pulping results was shown in Table 1. The $\mathrm{NaOH}$ cooking was reasonable in terms of pulp yield and delignification rates compared to the $\mathrm{NaOH}-$ Urea cooking. Though, at the same cooking time, $\mathrm{NaOH}$ pulping was shown high delignification rates, net yields subtracted lignin fraction were lower than those of $\mathrm{NaOH}-\mathrm{Urea}$.

The addition of $4 \%$ urea produced a higher pulp yield than that of $\mathrm{NaOH}$ for the almost same degree of delignification. And the increase in urea addition, especially such as $8 \%$, resulted the pulp with an unacceptably high residual lignin. The optimum pulping conditions were $90 \mathrm{~min}$. cooking at $170{ }^{\circ} \mathrm{C}$ using $4 \%$ urea in $18 \%$ active alkali.

Table 1. Cooking of oak wood with $\mathrm{NaOH}-\mathrm{Urea}$

\begin{tabular}{lcccc}
\hline $\begin{array}{c}\text { Cooking } \\
\text { chemical }\end{array}$ & $\begin{array}{c}\text { Cooking } \\
\text { time } \\
\text { min }\end{array}$ & $\begin{array}{c}\text { Pulp } \\
\text { yield } \\
\%\end{array}$ & $\begin{array}{c}\text { Klason } \\
\text { lignin } \\
\%\end{array}$ & $\begin{array}{c}\text { Delignification } \\
\%\end{array}$ \\
\hline \multirow{2}{*}{$\mathrm{NaOH}$} & 90 & 51.7 & 3.77 & 91.8 \\
& 120 & 50.2 & 5.27 & 88.9 \\
& 150 & 51.9 & 6.75 & 85.3 \\
$\mathrm{NaOH}+$ & 90 & 54.2 & 4.38 & 90.0 \\
$4 \%$ Urea & 120 & 59.1 & 7.41 & 81.6 \\
& 150 & 59.3 & 8.87 & 77.9 \\
$\mathrm{NaOH}+$ & 90 & 71.0 & 12.5 & 62.7 \\
$8 \%$ Urea & 120 & 70.0 & 11.1 & 67.4 \\
& 150 & 69.5 & 11.8 & 65.6 \\
\hline
\end{tabular}

\section{Effect of urea addition}

As shown in Table 2, it was observed that addition of urea in low alkali charges, such as $0.5 \mathrm{~N}$, retarded delignification rate compared to $\mathrm{NaOH}$ pulping.

But, in high alkali application such as $1 \mathrm{~N} \mathrm{NaOH}$, delignification was significantly enhanced. It was believed that these results were attributed to not the addition of urea but the high alkalinity. In addition, the changes in final $\mathrm{pH}$ of cooking liquor were big enough to disturb the delignification by addition of urea. Namely urea consumed much alkali during cooking as shown in Table 2. Though there were no changes in final $\mathrm{pH}$ of cooking liquor in the case of $1 \mathrm{~N} \mathrm{NaOH}$ application, final $\mathrm{pH}$ was abruptly reduced for the $\mathrm{NaOH}-$ Urea cooking in low alkali charge such as $0.5 \mathrm{~N} \mathrm{NaOH}$.

In order to know what component in wood consume the alkali, wood chip, woodmeal, organosolve lignin and avicel were treated with $\mathrm{NaOH}$ and $\mathrm{NaOH}$-Urea as shown in Table 3. In the case of $\mathrm{NaOH}$ only there were no changes in $\mathrm{pH}$ except woodmeal.

By adding urea in $\mathrm{NaOH}$, it was noticeable that there were a great decreasing in final $\mathrm{pH}$, especially in woods and avicel. It meant that the urea did not react with lignin fraction, but played a role to have react with carbohydrates, mainly cellulose, and have them consume the alkali.

Reaction of urea with cellulose in an aqueous medium at different temperatures has been widely studied by many researchers for the modification of cellulosic textile finishing (Hebeishi et al., 1978; Nozawa and Higashide, 1981) and the improving mechanical properties of paper (Fisher, 1951). While at $100{ }^{\circ} \mathrm{C}$ hydrogen bonds between urea and cellulose hydroxyls took place, at $150{ }^{\circ} \mathrm{C}$ the system was very complex, since crosslinking of cellulose, cellulose derivateves of urea, dimerization, as well as decomposition of urea could be realized. It was also reported that urea reacted with alcohols and polyhydric alcohols to bring about the corresponding carbamate esters (Jacobson, 1938; Nuessssle, 1961; Segal and Eggerton, 1961). There would be some possibility that carbamates and cellulose carbamates derived during cooking consumed the alkali. It was not known why woodmeal consumed so much chemicals in the presence of urea compared to the wood chips.

Table 2. Effect of Urea on final $\mathrm{pH}$ of cooking liquor during $\mathrm{NaOH}$ cooking $\left(170^{\circ} \mathrm{C}, 90 \mathrm{~min}\right.$.)

\begin{tabular}{lccc}
\hline \multicolumn{1}{c}{ Cooking } & Yield, $\%$ & $\begin{array}{c}\text { Kraft lignin } \\
\%\end{array}$ & Final $\mathrm{pH}$ \\
\hline $0.5 \mathrm{~N} \mathrm{NaOH}$ & 55.5 & 3.62 & 14.0 \\
\hline $\begin{array}{l}0.5 \mathrm{~N} \mathrm{NaOH} \\
+4 \% \mathrm{Urea}\end{array}$ & 62.8 & 11.9 & 13.3 \\
\hline $1.0 \mathrm{~N} \mathrm{NaOH}$ & 47.9 & 2.89 & 14.0 \\
\hline $\begin{array}{l}1.0 \mathrm{~N} \mathrm{NaOH} \\
+4 \% \text { Urea }\end{array}$ & 49.3 & 3.81 & 14.0 \\
\hline
\end{tabular}

Table 3. Changes in $\mathrm{pH}$ of cooking liquor after NaOH-Urea cooking

\begin{tabular}{ccc}
\hline Sample & $\mathrm{NaOH}$ & $\mathrm{NaOH}+$ Urea \\
\hline Wood chip & 14.0 & 13.3 \\
Woodmeal & 13.5 & 12.7 \\
Organolignin & 14.0 & 14.0 \\
Avicel & 14.0 & 13.5 \\
\hline
\end{tabular}

Table 4. Relative yields of guaiacol from guaiacylglycerol- $\beta$ guaiacyl ether (GG) by $\mathrm{NaOH}$ and $\mathrm{NaOH}-$ Urea cooking

\begin{tabular}{ccc}
\hline \multicolumn{2}{c}{ Cooking liquor } & $\begin{array}{c}\text { Relative yields } \\
\text { of Guaiacol, \% }\end{array}$ \\
\cline { 1 - 2 } $\mathrm{NaOH}$ & Urea, \% & 100 \\
$1 \mathrm{~N}$ & 0 & 95.3 \\
$1 \mathrm{~N}$ & 1 & 98.5 \\
$1 \mathrm{~N}$ & 2 & 98.0 \\
$1 \mathrm{~N}$ & 3 & \\
\hline
\end{tabular}


In order to confirm the effect of urea addition during $\mathrm{NaOH}$ cooking on delignification, lignin model compound, guaiacylglycerol- $\beta$-guaiacyl ether (GG ether), was subjected to $\mathrm{NaOH}$ and $\mathrm{NaOH}-$ Urea cooks. The yields of degradation product, guaiacol, from GG ether were as same as those by $\mathrm{NaOH}$ cooking as in Table 4. Therefore it was evident that urea did not participate on delignification reaction.

\section{Pulp properties}

Table 5 gave the pulping features compared with a kraft reference pulp. For the same degree of delignification, the yield of $\mathrm{NaOH}-$ Urea pulp was same or/and to some extent higher than the others. It is believed that higher yield of formers may attributed to the blocking effect of its peeling off reaction by some modification of reducing end groups of carbohydrates with the formation of cellulose carbamate ester. $\mathrm{NaOH}-$ Urea pulp had higher brightness than that of kraft.

Table 5. Pulping characteristics of oak wood with $\mathrm{NaOH}-\mathrm{Urea}$

\begin{tabular}{lccl}
\hline \multicolumn{1}{c}{ Properties } & $\mathrm{NaOH}$ & $\mathrm{NaOH}+4 \%$ Urea & Kraft \\
\hline Pulp yield, \% & 51.7 & 54.2 & 53.7 \\
Klason Lignin, \% & 3.77 & 4.38 & 4.05 \\
Brightness (Hunter), \% & 29 & 26 & 20 \\
\hline
\end{tabular}

Figure 1 showed the revolution numbers of PFI mill for the pulps. $\mathrm{NaOH}-$ Urea pulp was more difficult to beaten than kraft pulp, but relatively easier than $\mathrm{NaOH}$ pulp. In order to get $450 \mathrm{ml}$ freeness, the revolution numbers for kraft pulp was $1,230 \times 10^{2}, \mathrm{NaOH}-$ Urea pulp $1,450 \times 10^{2}$, and $\mathrm{NaOH}$ pulp $1,600 \times 10^{2}$. The resistance of pulp refining are closely related to the flexibility of pulp fibers. Kraft pulp had highest water retention value of 489. Those of $\mathrm{NaOH}-$ Urea and $\mathrm{NaOH}$ pulps were 434 and 338, respectively.

Table 6 was shown papermaking properties of various pulps. The hand sheet strength properties of $\mathrm{NaOH}$ pulp were slightly lower than for the other two pulps.

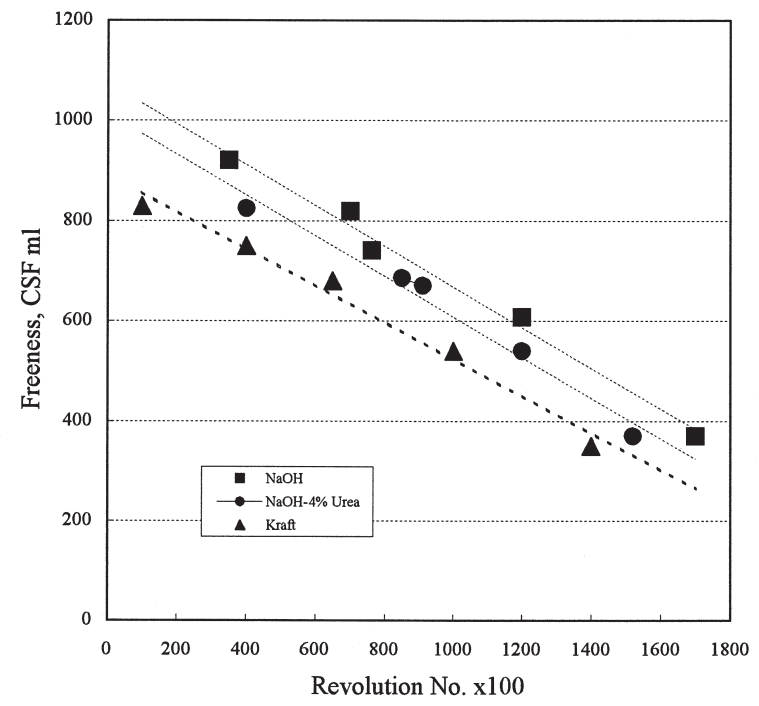

Fig. 1. Revolution number in PFI mill refining.
Table 6. Physical and mechanical properties of $\mathrm{NaOH}-\mathrm{Urea}$ pulp

\begin{tabular}{lccc}
\hline \multicolumn{1}{c}{ Properties } & $\mathrm{NaOH}$ & $\mathrm{NaOH}+4 \%$ Urea & Kraft \\
\hline Freeness, CSF ml & 380 & 400 & 360 \\
Sheet Density, g/cm & 0.71 & 0.75 & 0.85 \\
Breaking length, km & 6.98 & 8.44 & 9.71 \\
Tensile index, N.m/g & 68.4 & 82.8 & 95.2 \\
Tensile energy & & & \\
$\quad$ absorption, J/m² & 123 & 202 & 192 \\
Burst index, $\mathrm{kPa} . \mathrm{m}^{2} / \mathrm{g}$ & 4.67 & 6.19 & 6.47 \\
Tear index, $\mathrm{mN} . \mathrm{m}^{2} / \mathrm{g}$ & 4.54 & 8.80 & 6.92 \\
W R.V, \% & 338 & 434 & 489 \\
\hline
\end{tabular}

When compared at both the same freeness level, $\mathrm{NaOH}-$ Urea pulp had slightly lower tensile and burst strengths than kraft pulp, whilst tensile energy absorption and tear index were considerably increased. Apparent ssheet density of kraft pulp were higher than $\mathrm{NaOH}$ and $\mathrm{NaOH}-$ Urea pulps at the same level of freeness.

Breaking length failure will occur as the result of inadquate bonding or fiber failure. The latters becomes more significant as bonded area increases with a simultaneous increase in sheet density and tensile strength. As can be seen Fig. 2, there was a linear relationship between breaking length and sheet density. The slope of breaking length is affected by bonding strength. Those of NaOH-Urea and kraft pulp were shown almost same tendency. But $\mathrm{NaOH}$ pulp showed relatively inferior strength. Compared to paper strengths at the same level of sheet density, $\mathrm{NaOH}-U r e a$ pulp gave as almost same breaking length and tensile index as those of kraft pulp. Burst strength, however, was higher than the kraft at same level of density.

Though tensile and burst indices of NaOH-Urea pulp were lower than those of kraft pulp at the same level of freeness, burst strength of the former were higher than that of kraft pulp compared at the same tensile strength as shown in Fig. 3. The kraft pulp showed lower burst at high tensile index than $\mathrm{NaOH}-$ Urea pulp with higher burst at low tensile index, where-

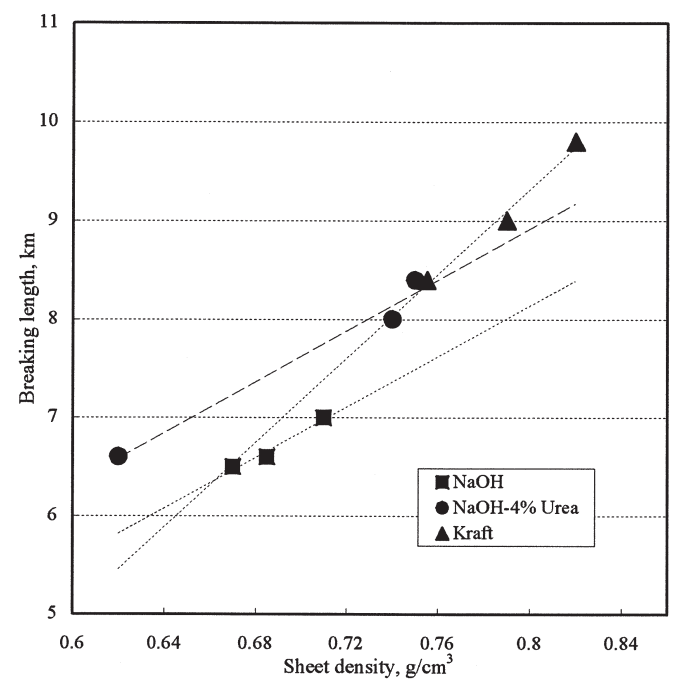

Fig. 2. Sheet density and breaking length. 


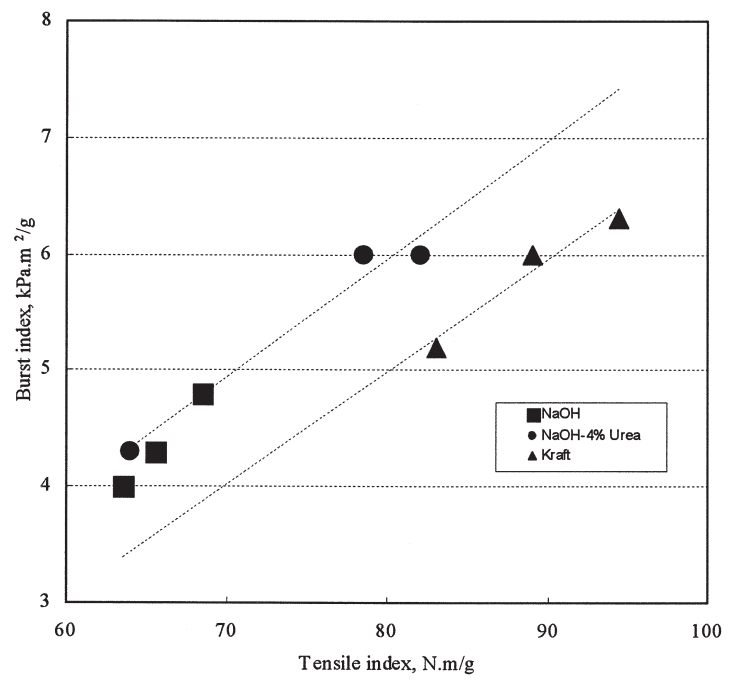

Fig. 3. Tensile index and burst index.

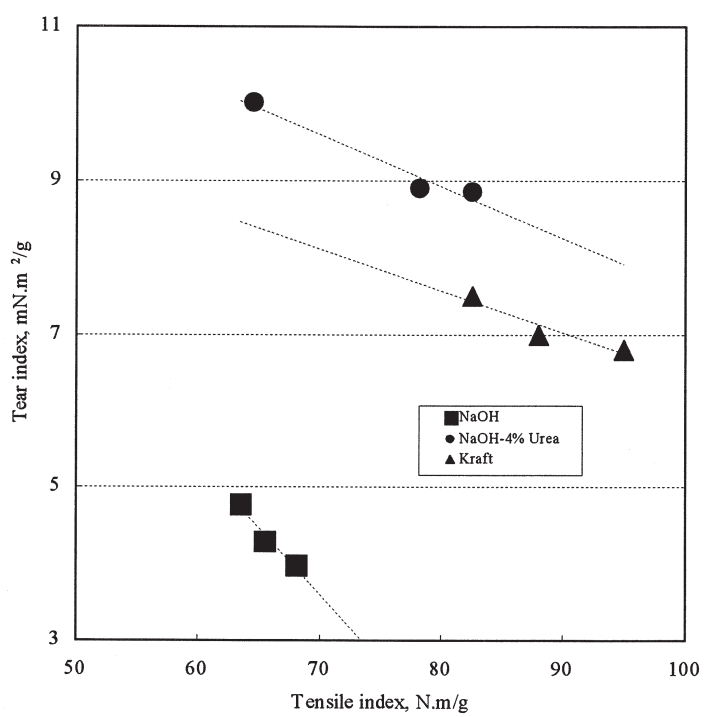

Fig. 4. Tensile index and tear index.

as $\mathrm{NaOH}$ pulp showed low burst at low tensile. Three pulps have all been prepared from same wood, but the tear/tensile relationship were markedly different as shown in Fig. 4. The NaOH-Urea pulp was the highest tear index at a low tensile index than $\mathrm{NaOH}$ and kraft pulps. The kraft pulp gave intermediate tearing resistance at relatively high tensile index, whereas the $\mathrm{NaOH}$ pulp had low tear and low tensile property. The cause could be related to tensile property. The higher tensile strength of a pulp would normally indicate either a longer fiber or a higher basic density of wood. In present experiment, since all three pulps were made by same wood, the effect of fiber length, fiber length distribution and of variability in their cross dimensions on the tensile strength would be needed for more detailed knowledge.

There was a linear relationship between tensile energy absorption and sheet density. Although breaking length and tensile index of $\mathrm{NaOH}-$ Urea and kraft pulp were shown almost same, tensile energy absorp-

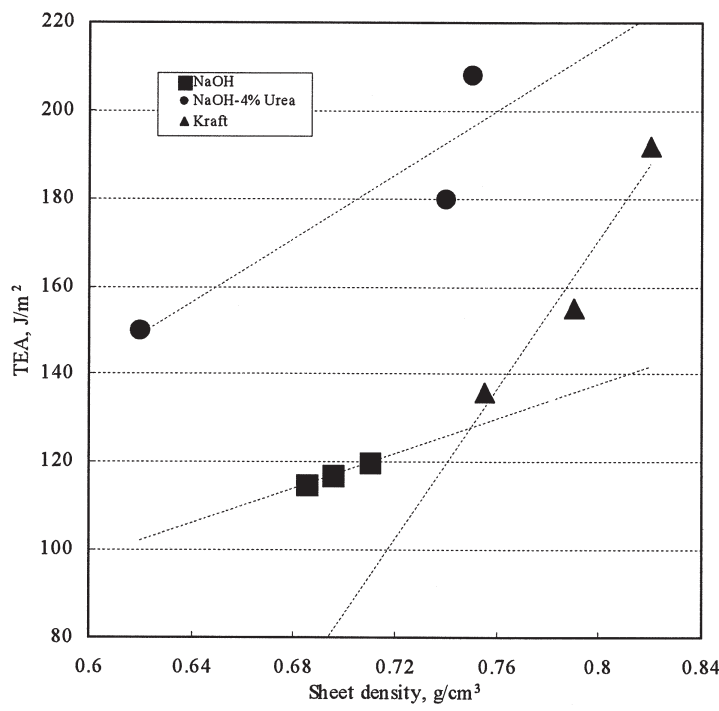

Fig. 5. Sheet density and tensile energy absorption.

Table 7. Carbohydrate composition of unbleached pulps

\begin{tabular}{lrccc}
\hline $\begin{array}{c}\text { Chemical } \\
\text { component } \\
\%\end{array}$ & Wood & $\begin{array}{c}\mathrm{NaOH} \\
\text { pulp }\end{array}$ & $\begin{array}{c}\mathrm{NaOH}+\text { Urea } \\
\text { pulp }\end{array}$ & $\begin{array}{c}\text { Kraft } \\
\text { pulp }\end{array}$ \\
\hline L-Arabinose & 2.03 & 0.1 & 0.1 & 0.32 \\
D-Xylose & 22.4 & 7.3 & 7.75 & 8.49 \\
D-Mannose & 1.2 & 0.1 & trace & 0.3 \\
D-Galactose & 0.9 & trace & trace & 0.1 \\
D-Glucose & 48.5 & 41.6 & 43.8 & 42.3 \\
L-Rhamnose & trace & trace & trace & trace \\
\hline Lignin & 23.8 & 1.95 & 2.37 & 2.18 \\
\hline
\end{tabular}

tion of the former as burst strength was much higher than that of the latters. But $\mathrm{NaOH}$ pulp showed relatively low strength. Compared to the strength at the same level of sheet density, $\mathrm{NaOH}-$ Urea pulp were shown very high tensile energy absoprtion as in Fig. 5.

Table 7 showed the carbohydrate compositions of different pulps compared with those of the original wood. For the kraft pulp hemicellulose contents were higher than for the $\mathrm{NaOH}$ and $\mathrm{NaOH}-$ Urea pulps. In the case of NaOH-Urea pulp glucan contents were higher than the others. These results would be contributed to the increase of pulp strength compared to that of $\mathrm{NaOH}$ pulp.

\section{CONCLUSIONS}

As an alternative method of kraft pulping process, $\mathrm{NaOH}$ pulping used cheap urea additive was adopted. The results were compared to the properties of $\mathrm{NaOH}$ and kraft pulps, and summarized as follows. $\mathrm{NaOH}-$ Urea cooking in low alkali charges, regardless of added amounts of urea, gave a relatively low delignification rate compared to $\mathrm{NaOH}$ pulping. But, in high alkali application, the delignification of oak wood was significantly enhanced. In the lignin model compound experiment, it was disclosed that urea did not participate on delignification reaction. The optimum condition was 90 
min. cooking at $170{ }^{\circ} \mathrm{C}$ using $4 \%$ urea in $18 \%$ active alkali. Beatability of $\mathrm{NaOH}-$ Urea pulp was a little faster than $\mathrm{NaOH}$ pulp, but slower than kraft pulp. Pulp brightness was a little higher than kraft pulp. Compared to sheet strengths at the same level of sheet density, $\mathrm{NaOH}-$ Urea pulp gave as almost same breaking length and tensile index as those of kraft pulp. Especially tensile energy absorption and burst index were higher than those of kraft pulp. Every property was superior than those of $\mathrm{NaOH}$ pulp.

This pulping method would appear to be one of the promising approach because the small amounts of urea in aqueous alkaline medium have the ability to stabilize carbohydrates against their peeling off reaction. Also, it is believed that, during pulping, the formation of cellulose carbamate would play a main role to enchance the paper strength.

\section{REFERENCES}

Abbot, J. and H. I. Bolker 1982 How amines accelerate delignification, Tappi, 65(2): 37-40

Abrahamson, K. and O. Samuelson 1979 Oxygen-alkali cooking of wood meal, Svensk Papperstidn., 4: 105-108

Aoyagi, T., S. Hosoya and J. Nakano 1977 Behavior of lignin during oxygen-sodium carbonate cooking, Mokuzai Gakkaishi, 23(3): 156-161

April, G. C., R. Bharcocha, J. Sheng and S. Hansen 1982 Prehydrolysis achieves higher organosolv delignification, Tappi, 65(2): 41-44

Cho, N. S. 1983 Nitric acid pulping of alkali-pretreated wood, J. Kor. Forestry Soc. 61: 27-36

Daima, H., S. Hosoya and J. Nakano 1978 Behavior of lignin during alkali-methanol cooking, Japan Tappi, 32(4): 49-52

Draganova, R., Z. Litovski and S. Zhelev 1971 Reaction between poplar wood and urea in the production of high yield pulps(1), -Behavior of wood and its carbohydrate components-, Tseluloza Khariya, 2(5): 10-13

Fisher, H. D. 1951 Effect of urea and related compounds on the mechanical properties of paper, Tappi, 34: 276-288

Flemming, B. I., G. Kubes, J. M. Macleod and H. I. Bolker 1978 Soda pulping with anthraquinone, Tappi, 61(6): 43-46
Ghosh, K. L., V. Venkaresh and J. S. Gratzl 1978 Quinone additives in soda pulping of hardwoods, Tappi, 61(8): 57-59

Hebeishi, A., A. I. Waly, N. Y. Abou-zeid and E. A. El-Alfy 1978 Reaction of cellulose carbamate with aromatic amines, Textile Res. J., 48: 468-472

Holton, H. H. and F. L. Chapman 1977 Kraft pulping with anthraquinone, Tappi, 60(11): 121-125

Hosoya, S. and J. Nakano 1980 Synthesis of $\beta$-guaiacyl ether type lignin model compound, Mokuzai Gakkaishi, 26(2) $118-121$

Huynh, V. B., A. Ishizu and J. Nakano 1982 Reaction of dilute nitric acid with apocynol, Mokuzai Gakkaishi, 28(3): 164168

Jacobson, R. A. 1938 Carbamic esters of urea, J. Am. Chem. Soc., 60: 1742-1744

Kalish, J. H., Nitric acid pulping. 1967 A new rapid cycle process, Tappi, 50(12): 44A-51A

Lyubavskaya, R. A. and V. V. Voronova, Process for producing semichemical pulp, USSR Pat. 560,024 (1977)

Nakano, J., C. Takatsuka and H. Daima 1976 Behavior of dissolution of lignin and carbohydrate during alkali-methanol cooking, Japan Tappi, 30(12): 33-38

Nozawa, Y. and F. Higashide 1981 Partially carbamate reaction of cellulose with urea, J. Appl. Polymer Sci., 26: 2103-2107

Nuessssle, A. C. 1961 Some aspects of the reaction between urea and cellulose, Textile Res. J., 31: 990-991

Obst, J. R. 1979 Quinones in alkaline pulping, Tappi, 62(1): $55-59$

Popescu, I., A. Groceac and F. Nita 1983 Pulp manufacturing technology for rice straw, Celuloza Hirtie, 32(3): 115-120

Sakakibara, A. 1983 Solvolysis pulping with lignin degradation products, Preprints of the 1983 ISWPC (Tokyo, Japan), vol. 3, 44-49

Segal, L. and F. V. Eggerton 1961 Some aspects of the reaction between urea and cellulose, Textile Res. J., 31: 460-471

Tripath, R. S. and S. Basu 1967 Pulping of bamboo in presence of additives, Indian Chem. Eng., 9(4): 106-109

Worster, H. E. and M. F. Pudek 1974a Sodium sulfite oxygen pulping for linerboard, Pulp Pap. Mag. Can., 75(1): 126130

Worster, H. E. and M. F. Pudek 1974b Delignification of high yield sodium sulfite pulps with alkali oxygen, Tappi, $\mathbf{5 7 ( 3 )}$ 138-141

Yaguchi, T. 1979 Mechanism of rapid delignification during alkaline cooking with addition of THAQ, Mokuzai Gakkaishi, 25(3): 239-242 
